www.jmscr.igmpublication.org

Impact Factor 5.244

Index Copernicus Value: 83.27

ISSN (e)-2347-176x ISSN (p) 2455-0450

crossref DOI: _https://dx.doi.org/10.18535/jmscr/v4i10.53

\title{
Clinico-Histopathological Study of Schwannoma at a Tertiary Care Centre, Gwalior
}

\author{
Authors \\ Dr Sudha Iyengar ${ }^{1}$, Dr Poonam Woike ${ }^{2}$, Dr Rajesh Gaur ${ }^{3}$ \\ ${ }^{1}$ Associate Professor, Department of Pathology, G.R Medical College, Gwalior M.P, India \\ ${ }^{2}$ Post Graduate Student, Department of Pathology, G.R Medical College, Gwalior, M.P, India \\ ${ }^{3}$ Professor \& Head, Department of Pathology, G.R Medical College, Gwalior, M.P, India \\ Corresponding Author \\ Dr Poonam Woike \\ Department of Pathology, G.R Medical College, Gwalior, M.P, India Phone No- 7745983670
}

\begin{abstract}
Schwannoma is one of the few truly encapsulated neoplasms of the human body and is almost always solitary. It's most common sites are flexor surfaces of the extremities, neck, mediastinum, retroperitoneum, posterior spinal roots and cerebellopontine angle. The aim of this study is to find out the prevalence of schwannoma in greater Gwalior region, to know the gender wise and age group wise distribution along with its site, various types and common presenting symptoms. The records of data of patients who underwent brain surgeries from january 2013- december 2014 were retrieved. They were compiled, summarized and statistically analyzed. In the present study the prevalence of schwannoma was $15.3 \%$ with male preponderance (65.8\%). The most common site was flexor surfaces of the extremities (50\%) and least were in retro peritoneum (5.3\%). Age group between 31-40 years (28.9\%) was mainly involved with the lesion. The most common presenting symptom was radiculopathy (73.7\%). Schwannoma is a benign tumor and surgery for schwannomas usually results in good postoperative functional outcomes.

Keywords- Schwannoma, radiculopathy, Neoplasm.
\end{abstract}

\section{INTRODUCTION}

Schwannomas, also termed as neurilemmomas, are benign nerve sheath neoplasms that originate from peripheral, cranial or autonomic nerves. These are well encapsulated tumors and malignant transformation is extremely rare. It's most common sites are flexor surface of the extremities, neck, mediastinum, retroperitoneum, spinal roots and cerebellopontine angle. Since it is a benign neoplasm that only rarely recurs, every attempt should be made to preserve the nerve. Grossly, the larger schwannomas often contain cystic areas.
The microscopic appearance is distinctive. Two different patterns usually can be recognized, designated by antoni $\mathrm{A}$ and antoni $\mathrm{B}$ areas. The antoni areas are quite cellular composed of spindle shaped cells arranged in a palisading or an organoid arrangement (verocay bodies). In type B areas the tumor cells are separated by abundant edematous fluid that may form cystic spaces. Occasionally, isolated cells with bizarre hyperchromatic nuclei are observed, they are particularly common in ancient schwannomas and are of no particular significance. 
Schwannoma is further divided into following types- ancient schwannoma, plexiform Schwannoma, classical schwannoma, cellular schwannoma and psammomatous melanotic schwannoma.

Tumors involving head and neck region consist of around $25 \%$ of all cases, usually originated from cranial (V, VII, IV, X, XI and XII) nerves, sympathetic or peripheral nerves ${ }^{[1-4]}$. These lesions are generally presented as a cosmetic deformity, an asymptomatic mass or symptoms related to nerve compression ${ }^{[5]}$. Advanced imaging investigations, such as magnetic resonance imaging (MRI) and/or computed tomography (CT) scan, are particularly useful in diagnosing these neoplasms and have become the routine studies for these patients ${ }^{[6]}$.

Spinal schwannomas account for about $25 \%$ of intradural spinal cord tumors in adults ${ }^{[7,8]}$. Most are solitary schwannomas, which can occur throughout the spinal canal ${ }^{[9]}$. Most schwannomas are firm, encapsulated neoplasm that are composed principally of neoplastic Schwann cells. The "multiple" form of neurofibromas is known as von Recklinghausen's disease ${ }^{[10]}$. According to Western studies, the incidence of spinal schwannomas varies between 0.3-0.4 cases/ 100,000 persons per year ${ }^{[11]}$. The age of its first manifestation was usually, with exception to few cases and few sites, around the $4^{\text {th }}$ and $5^{\text {th }}$ decades with no difference of prevalence between male and female ${ }^{[11,12]}$.

Immunohistochemically, the tumor cells show immunoreactivity for S-100 protein, calretinin, calcineurin, basal lamina components (laminin, growth factor receptor, lipocortin-1, and sometimes glial fibrillary acid protein and KP-1. The total excision of the lesion, which is the generally reachable goal of surgery, allows for clinical findings are not particularly severe.

\section{AIMS AND OBJECTIVES}

Present study was aimed to find out the prevalence of schwannoma in greater Gwalior region, to know the age group wise and gendertype IV collagen, and merosin), vimentin, nerve good results in the cases in which the preoperative

wise distribution of the lesion and to discern the common site and clinical symptoms of the patients presenting with the disease.

\section{MATERIALS AND METHODS}

Between January 2013 to December 2014, 249 patients underwent surgery for brain lesions at our institution. The information was collected retrospectively from medical records regarding clinical presentation, tumor location and operative findings. Out of 249 cases surgically excised, 38 were confirmed to be schwannomas by pathologists with histopathological sections in paraffin stained with hematoxylin-eosin. The data was compiled, summarized and analyzed using frequency distribution and percentage proportion.

\section{RESULTS}

A total number of 249 brain specimens were submitted from January 2013-december 2014 (2 years) for histopathological examination in department Of Pathology, G.R Medical College Gwalior. Out of 249 cases 38 were diagnosed as schwannoma. The mean age in present study was found to be $36.07 \pm 15.40 \mathrm{SD}$. The youngest patient in our study was 3 years old male and the eldest was 72 years old male. The male vs female ratio was 1.9:1. The gender-wise and age group wise distribution and site of lesion along with common clinical symptoms is illustrated in table no. 1, 2, 3 and fig. no.1.

Table No. 1- Gender wise Distribution of Schwannoma

\begin{tabular}{|l|c|c|c|}
\hline S.No & Gender & Total No. of Cases & Percentage (\%) \\
\hline 1. & Male & 25 & 65.8 \\
\hline 2. & Female & 13 & 24.2 \\
\hline
\end{tabular}

Table. No.2 -Distribution of Schwannoma in Various Age Groups

\begin{tabular}{|l|c|c|c|}
\hline S.No & $\begin{array}{c}\text { Age Group In } \\
\text { Years }\end{array}$ & $\begin{array}{c}\text { Total No. } \\
\text { Of Cases }\end{array}$ & $\begin{array}{c}\text { Percentage } \\
(\mathbf{\%})\end{array}$ \\
\hline 1. & $0-10$ & 01 & 2.6 \\
\hline 2. & $11-20$ & 04 & 10.5 \\
\hline 3. & $21-30$ & 10 & 26.3 \\
\hline 4. & $31-40$ & 11 & 28.9 \\
\hline 5. & $41-50$ & 04 & 10.5 \\
\hline 6. & $51-60$ & 07 & 18.4 \\
\hline 7. & $>60$ & 01 & 2.6 \\
\hline
\end{tabular}




\section{JMSCR Vol||04||Issue||10||Page 13130-13134||October}

Table No.3-Clinical Symptoms of Patients

\begin{tabular}{|l|c|c|c|}
\hline S.No & Symptom & $\begin{array}{c}\text { Total Number } \\
\text { Of Cases }\end{array}$ & $\begin{array}{c}\text { Percentage } \\
(\boldsymbol{\%})\end{array}$ \\
\hline 1. & Backpain & 13 & 34.2 \\
\hline 2. & Myelopathy & 03 & 7.9 \\
\hline 3. & Radiculopathy & 28 & 73.7 \\
\hline 4. & Motor weakness & 14 & 36.8 \\
\hline 5. & Voiding difficulty & 16 & 42.1 \\
\hline
\end{tabular}

\section{Distribution of site of schwannoma}

Total Number Of Cases

19

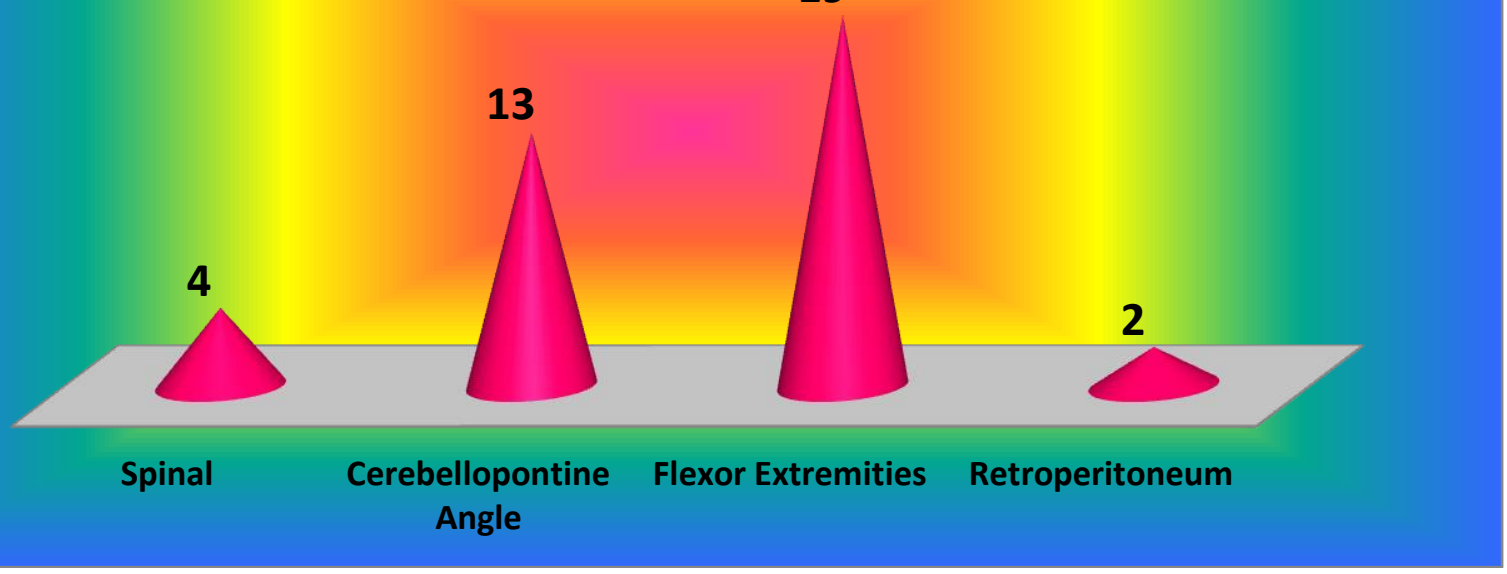

Fig. No. 1- Site of the Tumor

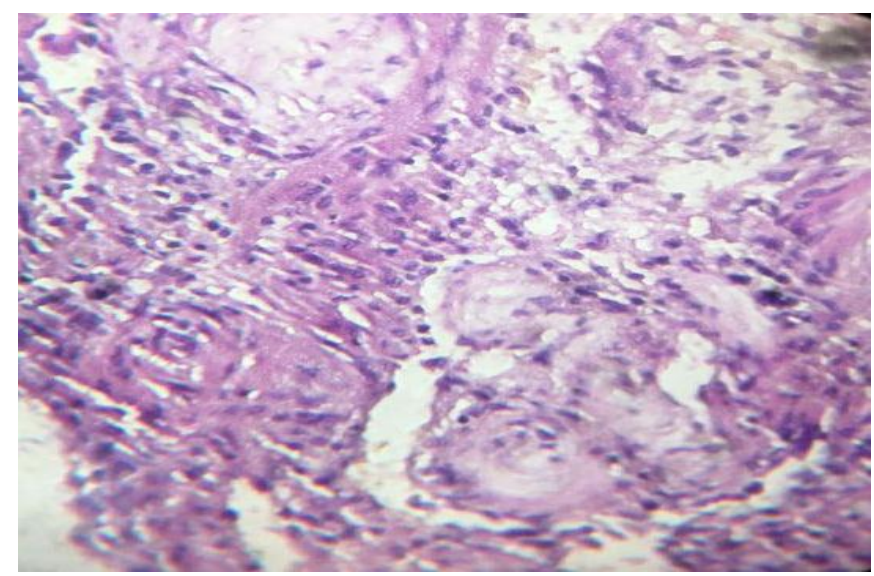

Fig no. 2. Pictomicrograph showing perivascular hyalinization in schwannoma $\mathrm{H} \& \mathrm{E}$ stain $40 \mathrm{X}$

\section{DISCUSSION}

Among the primary tumors, schwannoma and neurofibromatosis are the two most common neoplasms and both of which are benign and eccentrically arise from neural sheath $[5,13,14]$. Although schwannomas typically present as a solitary tumor, neurofibromas usually occur in the context of neurofibromatosis type $\mathrm{I}^{[5]}$.

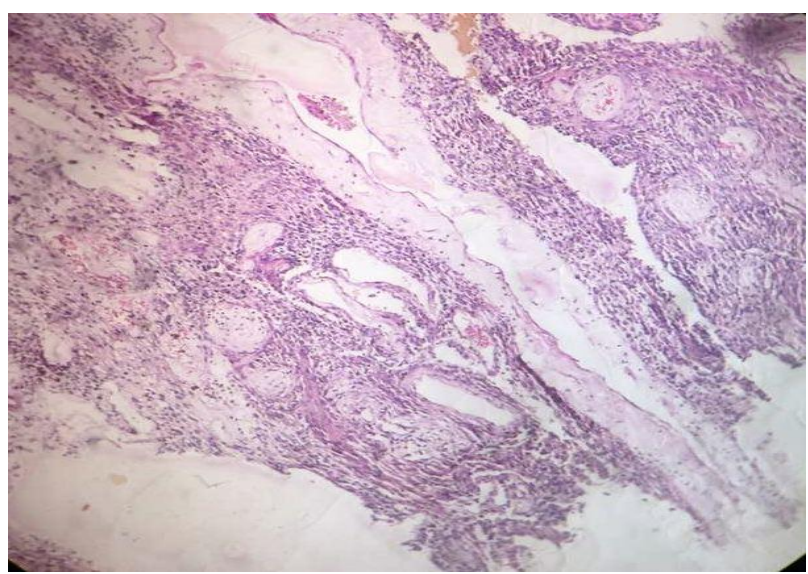

Fig no. 3. Pictomicrograph showing antoni $\mathrm{A}$ and antoni B areas along with perivascular hyalinization in schwannoma $\mathrm{H} \& \mathrm{E}$ stain $10 \mathrm{X}$

Schwannomas are usually indolent neoplasms that originate from cranial, peripheral or autonomic nerve sheaths. The eccentric position of the tumor in the nerve is probably contributing to the reason why the majority of cases with schwannoma. However, these tumors may have been investigated for space occupying lesion or nerve 
compression, months or even years prior to final diagnosis $^{[3],[4]}$. Even more complicated presentations, such as a cystic pectoral lesion ${ }^{[15]}$ or axillary $^{[16]}$ masses have also been reported. Considering the complexity of the regional anatomy, surgical resection of this tumor is a technically challenging procedure that has the potential for devastating neurological complications. In order to achieve the best result, an accurate preoperative planning, using imaging techniques such as MRI or CT scan is highly recommended. We could not find any published evidence regarding the precise incidence of postoperative neurological complications; however, some studies shows that temporary sensory or motor deficit frequently occurs after surgical resection of the schwannoma ${ }^{[3][5]}$. There are scattered reports of long term or permanent motor impairment after surgery as well ${ }^{[5]}$.

Spinal schwannomas account for about $25 \%$ of primary intradural spinal cord tumors in adults. There is no significant prevalence difference between males and females ${ }^{[7,8]}$. The incidence of schwannoma varies with the age of affected patients who are between the 4th and the 5th decade ${ }^{[17]}$. The initial symptoms are varied in accordance with the level of the tumor. The pain is localized in one (tumor) place, sometimes spread in both sides, mostly temporarily, but constantly in the same place and hurt as a knife. At the beginning the root pain is attributed to the disturbance of nerve conductivity because of the direct or indirect irritation of nerve root or root compression by the tumor ${ }^{[7]}$. Later on when compression increases to spinal cord, spinal tracts gets damaged and myelopathy develops [18,19]. However, motor weakness rarely occurrs as an initial symptom in the lumbosacral region. Motor weakness of the lower extremity may not be obvious until the later stage, as in patients with lumbar canal stenosis. Although total resection of spinal nerve sheath tumors has been considered to be feasible ${ }^{[18,19]}$, some cases have resected incompletely ${ }^{[20]}$. There may be two obstacles to total resection: one is adhesion to the spinal cord because of hemorrhage, inflammation, or subpial localization; the other is critical structures attached to extradural components outside the spinal canal in the cervical region, such as the vertebral artery. However, a good grasp of the anatomy of surrounding structures and meticulous surgical techniques could overcome these obstacles. In case of residual tumor, a long-term observation is needed ${ }^{[21]}$.

In present study we observed that the overall prevalence of schwannoma is $15.3 \%$. There is male versus female preponderance in the present study was $65.8 \%$ and $24.2 \%$ respectively. Frequent age group involved was between 31-40 years $(28.9 \%)$ followed by $21-30(26.3 \%), 51-60$ (18.4\%), 11-20 (10.5\%), 41-50 (10.5\%) and least were found in patients below $10 \mathrm{yrs}(2.6 \%)$ and above 60 years $(2.6 \%)$. Most common clinical presentation of the patients was radiculopathy (73.7\%) followed by voiding difficulty $(42.1 \%)$, motor weakness $(36.8 \%)$, backpain $(34.2 \%)$ and myelopathy $(7.9 \%)$.

For most part, the imperative site involved in our study was flexor aspects of extremities (50\%) followed by cerebellopontine angle (34.2\%), spinal (10.5\%) and retroperitoneum (5.3\%) correspondingly.

\section{CONCLUSION}

Schwannomas are benign nerve tumors. Their diagnosis is often delayed by the absence of clinical symptoms due to the nervous adaptation to the increased volume of the tumor. Hence, the need to think about this type of tumor before any mass in the path of peripheral nerve is essential. Surgery for schwannomas usually results in good postoperative functional outcomes. Although there could be recurrence in cases of previous subtotal removal, these also show good or stable prongosis.

\section{REFERENCES}

1. Bradley, W. and Midah, R. (2008) Chap 49: Schwannoma. In: Midah, R., Ed., Surgery of Peripheral Nerve: A Case Based Approach, Thieme, New York, 231. 
2. Bocciolini, C., et al. (2005) Schwannoma of Cervical Sympathetic Chain: Assessment and Management. Acta Otorhinolaryngologica Italica, 25, 191-194.

3. Jaafar, R., et al. (2012) Cervical Schwannoma: Report of Four Cases. Medical Journal of Malaysia, 67, 345-348.

4. Patel, M.L., Sachan, R., Seth, G., et al. (2014) Schwannoma of the Brachial Plexus: A Rare Cause of Monoparesis.BMJ Case Reports.

5. Soltani, A.M., et al. (2013) Neural Sheath Tumors of the Brachial Plexus: A Multidisciplinary Team-Based Approach. Annals of Plastic Surgery, 71, 80-83.

6. Chiofalo, M.G., Longo, F., Marone, U., Franco, R., Petrillo, A. and Pezzullo, L. (2009) Cervical Vagal Schwannoma: A Case Report. Acta Otorhinolaryngologica Italica, 29, 33-35.

7. Celli P, Trillo G, Ferrante L. Spinal extradural schwannoma. J Neurosurg Spine. 2005;2:447-456.[PubMed]

8. De Verdelhan O, Haegelen C, CarsinNicol B, Riffaud L, Amlashi SF, Brassier $\mathrm{G}$, et al. MR imaging features of spinal schwannomas and meningiomas. J Neuroradiol. 2005;32:42-49. [PubMed]

9. Dorsi MJ, Belzberg AJ. Paraspinal nerve sheath tumors. Neurosurg Clin N Am. 2004;15:217-222.[PubMed]

10. Conti P, Pansini G, Mouchaty H, Capuano C, Conti R. Spinal neurinomas: retrospective analysis and long-term outcome of 179 consecutively operated cases and review of the literature. Surg Neurol. 2004;61:34-43. discussion 44. [PubMed]

11. Seppala MT, Haltia MJ, Sankila RJ, Jaaskelainen JE, Heiskanen O. Long-term outcome after removal of spinal schwannoma : a clinicopathological study of 187 cases. J Neurosurg. 1995;83:621626. [PubMed]

12. Sharma S, Sarkar C, Mathur M, Dinda AK, Roy S. Benign nerve sheath tumors : a light microscopic, electron microscopic and immunohistochemical study of 102 cases. Path. 1990;22:191 195.[Pub Med]

13. Binder, D.K., Smith, J.S. and Barbaro, N.M. (2004) Primary Brachial Plexus Tumors: Imaging, Surgical, and Pathological Findings in 25 Patients. Neurosurgical Focus, 16, E11.

14. Lusk, M.D., Kline, D.G. and Garcia, C.A. (1987) Tumors of the Brachial Plexus. Neurosurgery, 21, 439-453.

15. Chen, F., Miyahara, R., Matsunaga, Y. and Koyama, T. (2008) Schwannoma of the Brachial Plexus Presenting as an Enlarging Cystic Mass: Report of a Case. Annals of Thoracic and Cardiovascular Surgery, 14, 311-313.

16. Kumar, A. and Akhtar, S. (2011) Schwannoma of Brachial Plexus. Indian Journal of Surgery, 73, 80-81.

17. Klekamp J, Samii M. Surgery of spinal nerve sheath tumors with special reference to neurofibromatosis. Neurosurgery. 199 8;42:279-289. Discussion 289-290. [PubMed]

18. Hori T, Takakura K, Sano K. Spinal neurinomas--clinical analysis of 45 surgical cases. Neurol Med Chir (Tokyo) 1984;24:471-477. [PubMed]

19. Subaciute J. [Early diagnosis of spinal cord schwannoma : the significance of the pain syndrome]Medicina (Kaunas) 2002; 38:1086-1088. [PubMed]

20. Lot G, George B. Cervical neuromas with extradural components: surgical management in a series of 57 patients. Neurosurgery. 1997;41:813-820. discussion 820822. [PubMed]

21. Jinnai T, Koyama T. Clinical characteristics of spinal nerve sheath tumors: analysis of 149 cases. Neurosurgery. 2005;56:510-515. discussion 510515. [PubMed] 